Universidad de Lima

Facultad de Ciencias Empresariales y Económicas

Carrera de Administración

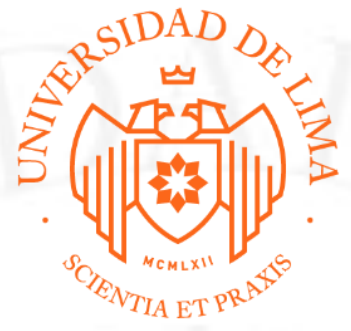

\title{
SUSTENTACIÓN DE CASO: PROPUESTA DE UN PLAN ESTRATÉGICO DEL INGRESO AL MERCADO PERUANO DE UNA EMPRESA DEL SECTOR FAST FASHION
}

Trabajo de suficiencia profesional para optar el Título Profesional de Licenciado en Administración

Gabriela Stephanie Taboada Dusek

Código 20121250

$$
\text { Lima - Perú }
$$

Diciembre del 2018 


\section{SUSTENTACIÓN DE CASO: PROPUESTA DE UN PLAN ESTRATÉGICO DEL INGRESO AL MERCADO PERUANO DE UNA EMPRESA DEL SECTOR FAST FASHION}




\section{TABLA DE CONTENIDO}

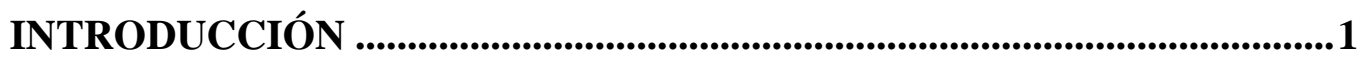

CAPÍTULO I: DIAGNÓSTICO ESTRATÉGICO ......................................2

1.1 Diagnóstico Interno ............................................................................. 2

1.1.1 Análisis del Modelo de Negocio ..........................................................2

1.1.2 Análisis de la Cadena de Valor ............................................................4

1.1.3 Ventajas competitivas de la empresa y por UEN ...................................6

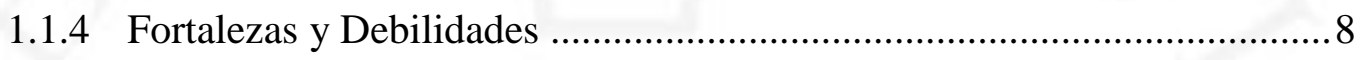

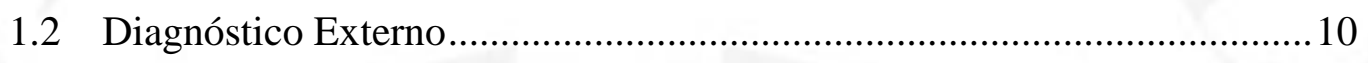

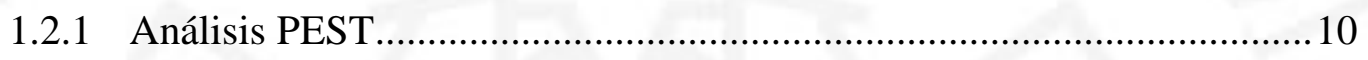

1.2.2 Análisis de las Fuerzas Competitivas del sector industrial .................... 13

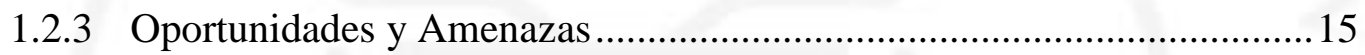

CAPITULO II: FORMULACIÓN DE LA ESTRATEGIA.............................16

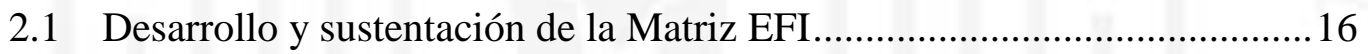

2.2 Desarrollo y sustentación de la Matriz EFE............................................. 17

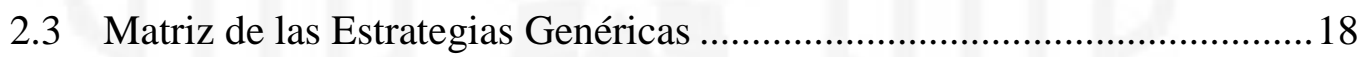

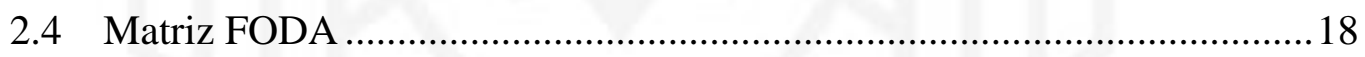

2.5 Definición y sustentación Visión, Misión y Políticas ..................................20

2.6 Definición de los Objetivos Estratégicos de la Empresa ...........................20

2.7 Redefinición o creación de nuevas UEN ...............................................21

2.8 Propuesta y sustentación de Estrategias ...................................................22

CAPÍTULO III: IMPLEMENTACIÓN ESTRATÉGICA ..............................24

3.1 Evaluación del rediseño de la estructura organizacional de la empresa

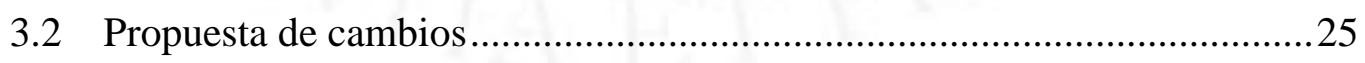

CAPÍTULO IV: CONTROL ESTRATÉGICO ..................................................26

4.1 Diseño de un Mapa Estratégico de Control ..............................................26

4.2 Desarrollo de un Cuadro de Mando Integral isẹp........................................22

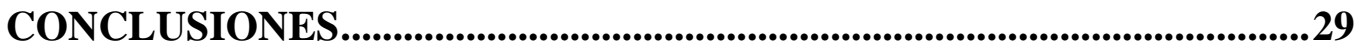


RECOMENDACIONES................................................................................30

REFERENCIAS BIBLIOGRÁFICAS ............................................................332

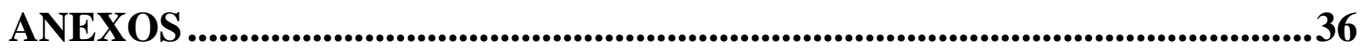




\section{ÍNDICE DE TABLAS}

Tabla 2.1 Matriz de Evaluación de Factores Internos ............................................. 16

Tabla 2.2 Matriz de Evaluación de Factores Externos ............................................ 17

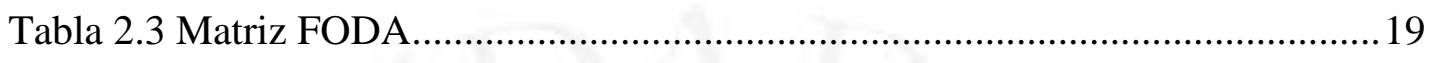

Tabla 4.1 Cuadro de Mando Integral ................................................................ 27 


\section{ÍNDICE DE FIGURAS}

Figura 1.1 Modelo de Negocios-Lienzo de Alexander Osterwalder ..........................2

Figura 3.1 Estructura Organizacional Propuesta .................................................24

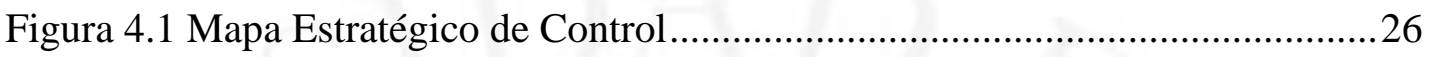




\section{ÍNDICE DE ANEXOS}

Anexo 1: The duration of an end to end fashion cycle 


\section{INTRODUCCIÓN}

En el presente trabajo se realizará un análisis estratégico de Fast Retailing, empresa de origen japonés con más de 30 años de experiencia en la industria del retail considerada, según los resultados del sector en el año 2017, como uno de los más grandes fabricantes de ropa a nivel global (Fast Retailing, 2018).

Actualmente, Fast Retailing opera en el rubro textil principalmente con siete marcas: Uniqlo, Theory, Comptoir Des Cotonniers, Princesse Tam Tam, GU, PLST y J Brand. Cada una de ellas con enfoques diferenciados y con puntos de venta alrededor de Asia, Europa y Norteamérica (Fast Retailing, 2018). Su oficina principal se encuentra ubicada en Japón, país de origen de su fundador y CEO Tadashi Yanai, actualmente considerado en el puesto número 28 del índice de multimillonarios de Bloomberg (Bloomberg, 2018).

La corporación fundada por Tadashi Yanai es considerada un caso de éxito a nivel mundial ya que logró convertir la tienda de ropa masculina que heredó de su padre, llamada Ogori Shoji, en una compañía reconocida a nivel mundial (Takeuchi, 2012, p. 2). En la actualidad, la marca Uniqlo se encuentra considerada en el puesto número 96 de las marcas más valiosas del mundo, compitiendo en sector textil sólo después de grandes marcas como Nike, Zara, H\&M y Adidas (Forbes, 2018).

Con el objetivo de evaluar el ingreso de Fast Retailing al mercado peruano en el año 2019, se procederá a realizar un diagnóstico externo del mercado e interno tanto para la corporación como para sus unidades estratégicas de negocio, en base a información del caso "Grupo Fast Retailing” (713 - S21) de Harvard Business School, elaborado por Hirotaka Takeuchi, y fuentes complementarias. Se propondrá la formulación e implementación de la estrategia a aplicar en este ingreso tentativo al mercado de retail fast fahion del Perú, para posteriormente presentar un plan de control estratégico asociado a dicha operación. 


\section{CAPÍTULO I: DIAGNÓSTICO ESTRATÉGICO}

\subsection{Diagnóstico Interno}

\subsubsection{Análisis del Modelo de Negocio}

En base al lienzo de modelo de negocio que propuso Alexander Osterwalder, se procederá a analizar los focos de esta plantilla en base a la propuesta de valor de Fast Retailing.

\section{Figura 1.1}

Modelo de Negocios-Lienzo de Alexander Osterwalder

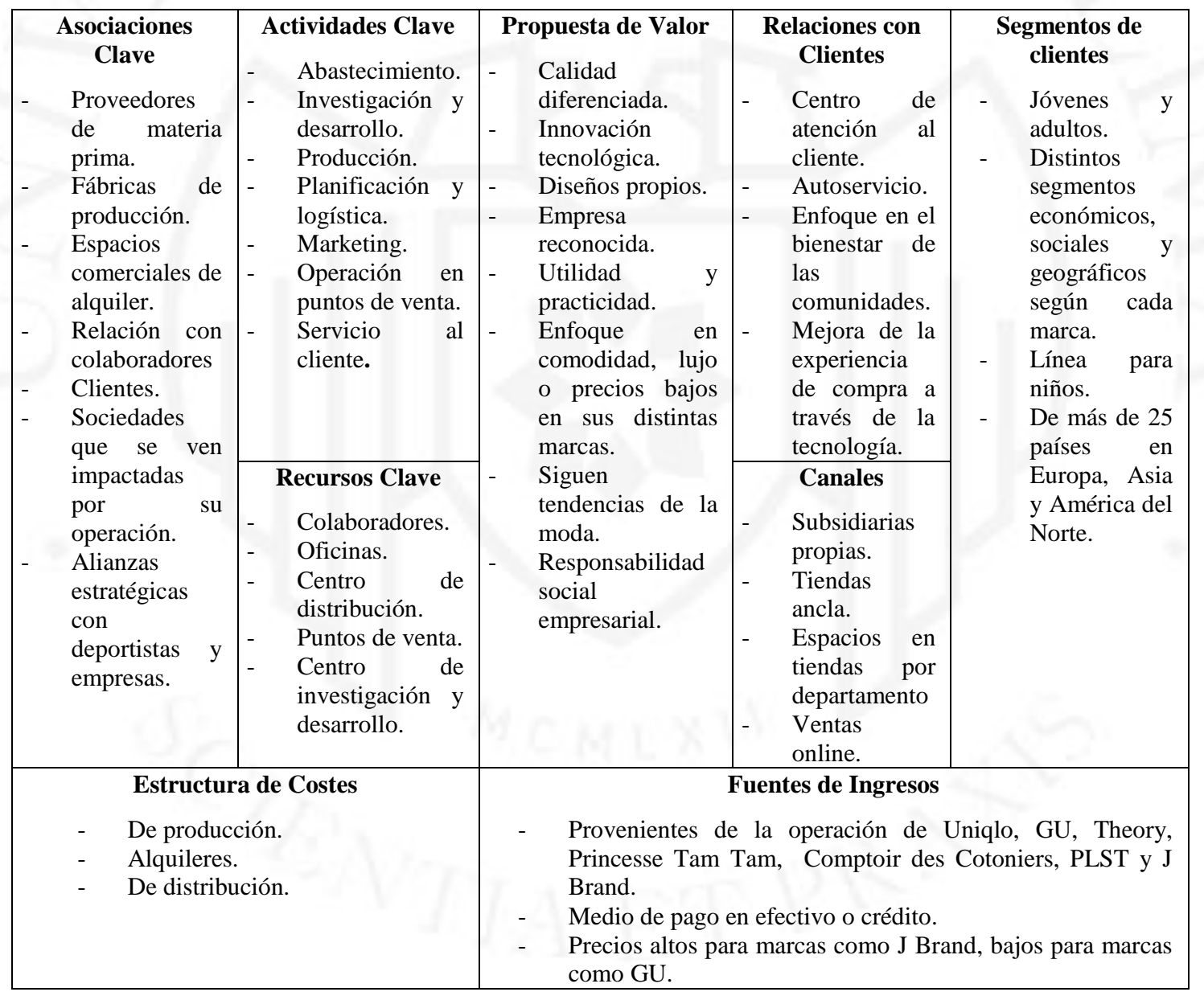

Fuente: Osterwalder y Pigneur (2010)

Elaboración propia 
Empezando por las asociaciones clave, Fast Retailing mantiene relaciones estrechas con diversos proveedores alrededor del mundo de manera que puedan acceder a materias primas de alta calidad. En el caso de Uniqlo, cuentan con asociaciones contractuales con compañías encargadas de fabricar sus productos en países como China, Vietnam y Tailandia (Fast Retailing, 2018).

En las actividades clave, la empresa sigue el modelo SPA (Specialty Store Retailer of Private Label Apparel) el cual se basa en tomar el control total de sus procesos del negocio, desde el diseño hasta la venta del mismo (Fast Retailing, 2018).

En cuanto a los recursos clave, la empresa cuenta con 114,830 colaboradores a nivel mundial (Fast Retailing, 2018). Como recursos físicos, cuenta con su casa matriz en Japón, oficinas corporativas, centro de distribución, y con más de 3000 puntos de venta a nivel mundial (Fast Retailing, 2018).

La propuesta de valor de Fast Retailing se enfoca en su principal pilar estratégico: la calidad. La empresa busca ofrecerle al cliente prendas de vestir duraderas, únicas, y siempre enfocados en la protección y respeto del medio ambiente, comunidades y sus recursos humanos. Los diseños propios e innovación tecnológica le permiten a la empresa ofrecer productos con un valor agregado diferenciado.

En cuanto a los canales para llegar a sus clientes, la empresa cuenta con subsidiarias propias, puntos de venta en centros comerciales, tiendas ancla en las principales avenidas de grandes ciudades, páginas web para cada marca, servicio de entrega a domicilio por medio de la compra online, una aplicación móvil, entre otros. Por otro lado, marcas como $\mathrm{J}$ Brand ofrecen sus productos en reconocidas tiendas por departamento como Barneys New York, Nordstrom y Harrod's.

Los segmentos de clientes son distintos para cada una de las marcas que maneja Fast Retailing. Uniqlo se dirige a hombres y mujeres de 20 a 60 años que busquen ropa cómoda y práctica (Takeuchi, 2012, p. 10). Theory y Helmut Lang se enfoca en adultos que busquen un estilo elegante. Comptoir des Cottoniers se dirige a la mujer moderna con estilo citadino, que busca exclusividad a precios moderados. Princesse Tam Tam se enfoca exclusivamente en la mujer, que busca calidad y exclusividad en artículos de lencería y relacionados. GU se enfoca en jóvenes y adultos que busquen calidad a precios bajos. PLST se dirige principalmente a jóvenes japoneses que siguen las últimas 
tendencias de moda. Por último, J Brand se enfoca en hombres y mujeres jóvenes que buscan exclusividad y calidad en telas y confección de pantalones de jean (Fast Retailing, 2018).

Para cada uno de estos segmentos, la marca presta especial atención a sus relaciones con los clientes. Por ejemplo, en Uniqlo cuentan con un centro de atención al cliente para recibir la retroalimentación necesaria con el objetivo de mejorar su servicio y también los productos. Por otro lado, la empresa se enfoca especialmente en las sociedades que se ven impactadas por su operación mediante actividades de responsabilidad social, capacitaciones, diseño de las tiendas en pro al ahorro de energía, uso de materiales reciclados, manejo de los desperdicios, entre otros (Uniqlo, s.f.).

Por otro lado, en cuanto a la estructura de costes, los costos más fuertes en los que incurre la organización vendrían a ser los de producción, alquiler de puntos de venta y espacios en tiendas por departamento, y distribución de productos desde la fábrica al centro de distribución, y posteriormente a cada tienda.

Por último, las fuentes de ingresos de Fast Retailing provenientes de la comercialización de sus productos se derivan principalmente de la operación de la marca Uniqlo (Japón e Internacional) la cual obtuvo un resultado en el año fiscal 2017 del $70 \%$ de los ingresos totales. El $30 \%$ restante se compuso por sus marcas GU, Theory, CPC, Princesse Tam Tam, PLST y J Brand. Es importante mencionar que los resultados de Uniqlo se originaron en un 53\% de la operación de Japón y en un $47 \%$ de la operación internacional (Fast Retailing, 2018).

\subsubsection{Análisis de la Cadena de Valor}

El modelo de la cadena de valor de propuesto por Michael Porter en el año 1985 permite realizar un análisis interno de la empresa mediante la segregación de áreas en dos grupos: actividades primarias y secundarias.

En cuanto a las actividades de soporte, comenzando por la infraestructura, la empresa se encuentra liderada por un gobierno corporativo encabezado por Tadashi Yanai y 6 directores. Además, la corporación cuenta con un consejo de auditoría conformado por 3 auditores externos y 2 internos,y áreas de soporte de contabilidad y de auditoría interna (Fast Retailing, 2018). 
La empresa se enfoca especialmente en la gestión de sus recursos humanos y eso lo reflejan mediante sus buenas prácticas en reclutamiento, empoderamiento del colaborador, oferta de programas de capacitación atractivos y planes de línea de carrera, promoción del código de conducta, ética, diversidad, balance de la vida laboral, y seguridad y salud en el trabajo (Fast Retailing, 2018).

En cuanto al desarrollo tecnológico, la empresa busca ir al ritmo de los avances implementando soluciones tecnológicas no sólo en sus servicios, sino también en sus productos. En Uniqlo cuentan con la línea "HEAT TECH” en sus prendas de vestir, la cual utiliza una tecnología que permite que las fibras de la tela generen calor por si solas al absorber la humedad que el cuerpo emite (Uniqlo, s.f.).

Uno de los principales enfoques de la compañía es el de mantener un nivel de calidad óptimo en sus productos y esto empieza en su aprovisionamiento. La empresa realiza la negociación y compra de manera directa con fabricantes alrededor de todo el mundo que los proveen de materia prima de (Takeuchi, 2012, p. 6).

En cuanto a las actividades primarias, la logística interna comienza en el aprovisionamiento directo mencionado previamente. La posterior fabricación se lleva a cabo en distintas localidades, mayormente en China, mediante compañías con las que mantienen acuerdos contractuales (Fast Retailing, 2018).

Sobre la logística externa, como medio para llegar al consumidor final utilizan el canal online y físico. Cuenta con puntos de venta para Uniqlo, GU, Theory, Comptoir des Cotonniers y Princesse Tam Tam. Los productos de J Brand se encuentran disponibles en boutiques y tiendas de lujo a nivel mundial (Fast Retailing, 2018).

En cuanto al marketing y ventas, para el caso de Uniqlo se utiliza la publicidad mediante campañas promocionales por temporada, principales descuentos, o productos nuevos. Estas campañas se emiten por diversos medios como la televisión, periódico o publicidad web. Las ventas se realizan, adicionalmente a las tiendas físicas y el canal online, mediante el empleo de máquinas dispensadoras de casacas y polos "Uniqlo To Go" en distintos aeropuertos (Business Insider, 2017).

Finalmente, en cuanto a los servicios, destacan por el servicio y atención al cliente, tomando en cuenta sus comentarios y recomendaciones, buscando constantemente soluciones tecnológicas que mejoren la experiencia de compra, 
enfocándose en la disposición de ayuda de su personal, ofreciendo una política de devolución de productos de Uniqlo favorecedora para el cliente, entre otros.

\subsubsection{Ventajas competitivas de la empresa y por UEN}

La ventaja competitiva de una empresa se logra mediante la eficiencia, calidad, innovación y respuesta al cliente (Hills, Jones y Schilling, 2015, p.94).

Fast Retailing logra su ventaja competitiva a través de una calidad superior, ya que a partir del 2004 dejaron de lado su estructura de precios bajos por priorizar la calidad de sus productos como motor de la diferenciación de su oferta (Takeuchi, 2012, p. 6). Como se mencionó previamente, este nivel de calidad se logra con el soporte de la minuciosa selección de proveedores, desarrollo de productos innovadores, el constante control de los procesos de fabricación en base a su estándar de calidad y supervisión, y el enfoque en la satisfacción del cliente mediante la atención física, online y el servicio post venta.

En el caso de Uniqlo, esto se logra mediante el empleo de su departamento de innovación y desarrollo, encargados de realizar productos en base a tendencias globales, buscando mejorar la oferta existente en base a la experimentación y tecnología (Fast Retailing, 2018). Para asegurar el nivel de calidad en el que se enfoca la empresa, cuentan con un equipo de supervisión denominados "Takumi Team", conformado por ingenieros con más de 30 años de experiencia en el sector, quienes le ofrecen a estos fabricantes un soporte técnico y capacitación constante en temas relacionados a la confección. El servicio al cliente es un factor clave para la marca, el cual buscan ofrecer de una manera óptima mediante el apoyo de colaboradores dispuestos a atender las necesidades del cliente rápida y efectivamente. Además, prestan especial atención en la condición de la tienda en base a aspectos higiénicos, surtido de productos completo, gestión de inventario oportuno y distribución eficiente de las categorías en el punto de venta y servicio post venta (Takeuchi, 2012, p. 3).

Por otro lado, en cuanto a sus marcas globales, en el caso de Theory la calidad superior se ve reflejada en sus productos de lujo, empleando materias primas de alta calidad y ofreciendo prendas de vestir con un nivel de confección mucho mas especializado. En cuanto a la innovación, cuentan con un equipo de liderazgo creativo 
encargado de generar productos como el cuero artificial o la línea "Theory 2.0" (Theory, s.f.).

Comptoir de Cotonniers logra diferenciarse mediante su calidad a través de la selección cuidadosa de sus telas y el empleo de un equipo especializado de diseño en París encargado de generar colecciones exclusivas (Comptoir des Cotonniers, s.f.). La esencia de la marca dirigida a su foco, la mujer, mantiene a través de los años un mismo estándar y ha logrado fidelizar clientes de distintas generaciones desde sus inicios, como con la campaña "Madre e Hija" (Takeuchi, 2012, p. 8).

Princesse Tam Tam, consigue un nivel de la calidad diferenciado por su experiencia en la confección de corsetería. Sus productos están elaborados en un $60 \%$ en base a encaje francés de alta calidad y cada uno de ellos pasa por 10 pruebas de calidad semanales. En cuanto a la producción, los costureros expertos emplean 4 horas en fabricar un conjunto de lencería. Además, ha destacado a través de los años por su carácter innovador, ya que la marca reinventó el mercado de la lencería dejando de lado las prendas sencillas y poco atractivas e introduciendo productos coloridos que, para la época, se consideraban revolucionarios (Princesse Tam Tam, s.f.).

GU, la marca enfocada en precios bajos, además de la calidad proveniente del estándar corporativo, tiene un especial enfoque en la innovación. Este año inauguraran en Japón "GU STYLE STUDIO”, un modelo de tienda que conecta la experiencia de compra física con la online en la cual los consumidores podrán encontrar en la tienda física toda la línea de productos para que puedan probar y combinar, y posteriormente realizar su pedido online en base a su experiencia (Fast Retailing, 2018).

$\mathrm{J}$ Brand es mundialmente reconocida por usar denim premium en sus pantalones. La calidad asegurada y el reconocimiento han logrado que sus productos, a pesar de tener sustitutos, se consideren íconos de la moda y se ofrezcan a precios muy sobre el promedio. Además de ello, el valor agregado también se evidencia en el diseño ya que cuentan en su equipo con reconocidos diseñadores como Simone Roche, Bella Freud y realiza colaboraciones con Proenza Schouler (J Brand, s.f.).

Por último, PLST, la marca actualmente enfocada exclusivamente en el mercado japonés, también destaca por su calidad superior en cuanto a telas empleadas, estilos, texturas, y su foco en la producción de productos propios (Fast Retailing, 2018). 


\subsubsection{Fortalezas y Debilidades}

\section{Fast Retailing}

Fortalezas

- Empleo del modelo SPA mediante el cual controlan todos los procesos de la operación, desde el diseño hasta comercialización (Fast Retailing, 2018).

- Más de 30 años de experiencia en el mercado desde que establecieron la primera tienda de Uniqlo (Fast Retailing, 2018).

- Variedad de marcas dirigidas a distintos segmentos.

- Tercera compañía minorista de manufactura textil más grande a nivel mundial. Sólo después de Inditex y H\&M (Fast Retailing, 2018).

- Calidad diferenciada de sus productos.

- Foco en la cultura organizacional y condiciones laborales ofrecidas.

- Filosofía enfocada en socios estratégicos (Fast Retailing, 2018).

Debilidades

- Ofrecen los mismos productos para todos los mercados, ya que no se adaptan localmente con ninguna de sus marcas.

- Sus principales competidores incursionaron en mercados internacionales antes, ya que sus mercados locales se saturaron (Takeuchi, 2012, p. 10)

- Alta dependencia económica de Uniqlo, marca que representó el 70\% de los ingresos totales en el 2017 (Fast Retailing, 2018).

\section{Uniqlo}

Fortalezas

- El modelo fast fashion les permite manejar tiempos de diseño, producción, distribución y comercialización más reducidos que en marcas que aplican un modelo regular o de lujo (McKinsey\&Company, 2018).

- Marca prioritaria para la empresa, ya que representa el $81.5 \%$ de las ventas netas del grupo a Agosto del 2017 (Fast Retailing, 2018).

- La marca se dirige a un segmento de clientes más amplio que el de sus competidores (Takeuchi, 2012, p. 10). 
- Foco en prendas de vestir básicas, a diferencia de competidores que se enfocan en las últimas tendencias de la moda.

- Empleo de soluciones tecnológicas en materiales para sus productos.

Debilidades

- La producción se realiza mediante manufactureras a las cuales contratan, no cuentan con fábricas de producción propias (Fast Retailing, 2018).

- No realizan envíos internacionales desde su canal de ventas online.

- No ofrecen una gama de productos variada.

- Extenso presupuesto publicitario (Takeuchi, 2012, pp. 10 - 11).

\section{GU}

Fortalezas

- Productos de calidad a precios bajos (Fast Retailing, 2018).

- Enfoque en la mejora de la experiencia de venta mediante el uso de la tecnología (Fast Retailing, 2018).

- Respaldo del grupo Fast Retailing y de la reconocida marca Uniqlo.

Debilidades

- Disminución en ganancias en el año 2017 (Fast Retailing, 2018).

- Enfoque en el mercado asiático. Solo tienen presencia en China, Japón, Corea, Taiwán y Hong Kong (GU).

- Aún no se concreta una estrategia de expansión global que le permita tener presencia sólida en mercados internacionales (Fast Retailing, 2018).

\section{Marcas Globales}

Fortalezas

- Liderazgo de la marca J Brand en el sector (J Brand, s.f.).

- Posicionamiento de Theory en el mercado de Estados Unidos.

- Princesse Tam Tam es considerada una marca pionera en el mercado de la lencería (Princesse Tam Tam, s.f.). 
- Lanzamiento de la línea 2.0 de Theory enfocada en jóvenes profesionales con el objetivo de potenciar la presencia de la marca (Sherman, 2017).

- Colecciones exclusivas de Comptoir des Cotonniers.

- Respaldo del grupo Fast Retailing y de la reconocida marca Uniqlo.

- Todas las marcas cuentan con plataforma de ventas online.

Debilidades

- Orientación a nichos de mercado selectos por cada marca.

- PLST es una marca muy nueva en el mercado, establecida en abril del 2018 (Fast Retailing, 2018).

- Dependencia de J Brand en espacios comerciales de tiendas por departamento exclusivas como Nordstrom, Barney's y Harrods.

\subsection{Diagnóstico Externo}

\subsubsection{Análisis PEST}

Tomando en consideración el objetivo de Fast Retailing de ingresar al mercado peruano en el año 2019, se procederá a realizar un análisis de los factores del macro entorno que influyen en la evaluación de esta operación con énfasis en la coyuntura del mercado peruano.

\section{Factores políticos, legales y gubernamentales}

En el presente año, el gobierno del Perú ha presentado distintos momentos políticamente inestables y de constante cambio. La salida del ex presidente Pedro Pablo Kuczinsky, y la toma del cargo por el actual presidente Martín Vizcarra, provocó un ambiente de incertidumbre y especulación en el país. Juan Varilias, presidente de la Asociación de Exportadores, indicó en una entrevista que dentro de este ambiente cambiante es necesario que se den reformas para que el país avance y que se muestre más atractivo y confiable a las inversiones nacionales y extranjeras (Andina, 2018).

A partir del 01 de Enero del 2019, asumirá la alcaldía de Lima el abogado Jorge Muñoz Wells, quien tendrá una importante tarea mediante la ejecución de proyectos de infraestructura para facilitar el desarrollo de negocios. Otro factor a considerar es la 
informalidad laboral. Según el Ministerio del Trabajo y Promoción del Empleo, al cierre del año 2017 en el Perú se contaba con una tasa de informalidad laboral del $46.5 \%$ del total de asalariados, es decir, casi la mitad de los trabajadores con relación de dependencia no cuentan con un contrato laboral en el país (Redacción Perú21, 2018).

Además, se deben tomar en consideración los acuerdos comerciales con los que cuenta el gobierno peruano actualmente, los cuales permiten que se eleve el dinamismo comercial al otorgar beneficios en el intercambio de bienes con distintos países. Actualmente contamos con Tratados de Libre Comercio con Estados Unidos, China y Japón, países donde se encuentran las principales operaciones de Fast Retailing en cuanto fabricación y distribución (Ministerio de Comercio Exterior y Turismo, s.f.).

\section{Factores económicos}

El ingreso de Fast Retailing al Perú en el 2019 se evaluará considerando las tendencias económicas del país y en especial del sector de retail y fast fashion en la actualidad. Según el Ministerio de Economía y Finanzas el gobierno peruano tiene como objetivo aumentar el PBI en 5\% para el año 2021, y una de las medidas para lograrlo incluye la facilitación del comercio y mejora en la cadena logística. Indican que se busca modificar procesos aduaneros, reducir los plazos de liberación de mercancías, y controlar efectivamente operaciones relacionadas al comercio internacional (Ministerio de Economía y Finanzas, 2018, pp. 21 - 22).

El sector de comercio en el Perú, que representa aproximadamente el 10.8\% del PBI, ha crecido aceleradamente por cinco trimestres y estiman una expansión del 3.2\% al cierre de este año, porcentaje que supera el promedio de la región. El aumento en estas proyecciones proviene del alza en la tasa de empleo nacional, aumento del ingreso en zonas urbanas, recuperación del consumo y la creciente tendencia en el crédito de consumo. Por otro lado, a mayo del presente año, las tiendas por departamentos representaron el 9.4\% del total de ventas del sector retail (Peñaranda, 2018, pp. 6 - 8).

A julio de este año, se cuenta con 98 centros comerciales en el Perú , 53 de ellos solo en Lima y aproximadamente 15 proyectos relacionados hacia el 2021 (Peñaranda, 2018). El desarrollo y presencia de centros comerciales en el Perú tienen un impacto positivo en la economía nacional debido a que no solo atrae inversión, sino que genera 
puestos de trabajo formales. La Asociación de Centros Comerciales y de Entretenimiento del Perú estima que al cierre de este año, las ventas aumentarán en un 7.3\% en comparación al cierre del 2017 (Perú Retail, 2018).

\section{Factores sociales, culturales y demográficos}

El ingreso de Fast Retailing al Perú se debe evaluar en base a la concentración demográfica de los niveles socioeconómicos dispuestos a pagar el ticket promedio de los productos que sus marcas ofrecen. El porcentaje de población por nivel socioeconómico es un factor crucial ya que en base a ello se tomará deberá decidir la ubicación del primer punto de venta en su llegada al Perú.

En Lima Metropolitana, en el 2017 sólo el $0.8 \%$ de las personas pertenecían al nivel socioeconómico A1, el 3.6\% al NSE A2, 8.9\% al B1 y 15.6\% al NSE B2, esto sobre una totalidad de 10,190,922 ciudadanos según proyecciones del INEI. En estos sectores mencionados, el mayor porcentaje se concentra en distritos como Miraflores, San Isidro, San Borja, Surco, La Molina, Jesús María, Lince, Pueblo Libre, Magdalena, San Miguel, Surquillo, Barranco, Chorrillos y San Juan de Miraflores (APEIM, 2017).

Otro factor que se debe tomar en consideración son las tendencias de compra de los peruanos, las cuales han cambiado ya que están más informados, viaja más y esperan más de las marcas (Perú Retail, 2018).

\section{Factores tecnológicos}

Actualmente a nivel global, las empresas de retail y en especial para este caso, las del sector fast fashion, aprovechan los avances para poder ofrecerle a sus clientes un servicio diferenciado e innovador que mejore la experiencia tanto presencial como online mediante soluciones tecnológicas.

En el Perú, un factor importante que mantiene una tendencia de crecimiento en el sector retail es el de las compras online. Es necesario que las empresas se adapten a estas tendencias y busquen introducirse en el mundo virtual para poder llegar a más consumidores. Según Kantar Millward Brown e Interactive Advertising Bureau, actualmente contamos con 5 millones de usuarios peruanos que compran por Internet. 
Jaime Montenegro, Gerente de Comercio Electrónico de la Cámara de Comercio de Lima, indicó que se estima que al cierre del 2018 las compras por internet aumenten en 20\% en comparación al 2017 (Perú Retail, 2018).

\subsubsection{Análisis de las Fuerzas Competitivas del sector industrial}

Según el modelo que presentó Michael Porter, el análisis del nivel competitivo de una industria se ve relejado mediante 5 fuerzas del entorno que ayudar a identificar las oportunidades y amenazas existentes (Hills et alt., 2015, p. 47).

\section{Rivalidad entre competidores}

La rivalidad entre competidores del sector fast fashion es alta y con una estructura competitiva fragmentada, esto, debido a que a pesar de que la competencia es fuerte entre las marcas líderes del sector, la participación de mercado no está realmente concentrada en ellas. En el mercado peruano, Fast Retailing entraría a competir con sus principales rivales a nivel mundial: H\&M, Zara y The Gap; las cuales cuentan con puntos de venta en los principales centros comerciales y empresariales.

Las grandes tiendas por departamento como Saga Falabella y Ripley también representan competencia para la empresa debido a la variedad del mix de marcas, la cantidad de puntos de venta con los que cuentan tanto en Lima como en provincia, y el fortalecimiento de su comercio. Otras marcas reconocidas internacionalmente, que competirían directamente con Fast Retailing ya que se dirigen a un público objetivo similar son Forever21, Mango, Tommy Hilfiger y American Eagle Outfitters.

\section{Amenaza de nuevos competidores}

La amenaza de nuevos competidores en este caso es alta, ya que muchas marcas que en el extranjero compiten de manera directa con Uniqlo, pero que por el momento no tienen presencia en el mercado peruano, podrían ingresar en los próximos años debido al atractivo del Perú como sector de inversión y las oportunidades de ingreso al mercado (Ministerio de Economía y Finanzas, 2018). Ejemplo de ellas sería la reconocida marca estadounidense Old Navy, perteneciente al grupo Gap Inc. Por otro 
lado, tras la presencia de la Zara en el Perú, el ingreso de otras marcas del grupo Inditex como Pull\&Bear, Bershka o Stradivarius también representarían una amenaza en el sector del público joven y adulto.

\section{Poder de negociación de los clientes}

Podría considerarse que el poder de negociación que manejan los clientes de Fast Retailing es medio, ya que la oferta de marcas nacionales y extranjeras en el Perú en el sector de retail textil y fast fashion es bastante amplia. Existen muchos proveedores, no hay lealtad a la marca y el costo de cambio es bajo. Si bien sus marcas son mundialmente reconocidas por ofrecer una calidad superior, los productos que ofrecen pueden ser fácilmente reemplazados por otros.

\section{Poder de negociación de los proveedores}

El poder de negociación de los proveedores con la empresa es bajo. Fast Retailing trabaja con empresas designadas a las cuales les compran materias primas de calidad. Al ser la empresa un cliente importante para el proveedor y considerando el tipo de prendas de vestir que fabrican, podría conseguir sustitutos fácilmente en caso se presenten aumentos de precio, ya que en realidad no se trata de algo esencial que solo se consiga mediante proveedores selectos, como sucede en el sector tecnológico.

\section{Amenaza de productos sustitutos}

En el Perú, a diferencia de muchos países de la región, la industria textil es bastante fuerte y representa una amenaza alta para las empresas de retail en cuanto a la venta directa de productos que funcionan como sustitutos y que satisfacen las mismas necesidades. Un ejemplo claro de ello es Gamarra, el reconocido emporio textil en Lima con proyecciones de facturación de mas de 4000 millones anuales (Diario Gestión, 2018).

Por otro lado, un factor muy importante que representa una amenaza para el sector retail formal son la piratería y el contrabando. La comercialización de productos falsos es algo que se evidencia en distintos lugares de Lima y provincia, sólo en el 2017 
se incautaron mas de 25 millones de soles de mercadería pirata de China (Diario Gestión, 2018) y uno de los sectores más afectados por el contrabando es el textil.

\subsubsection{Oportunidades y Amenazas}

\section{Oportunidades}

- Proyecciones de crecimiento del PBI en el Perú (Ministerio de Economía y Finanzas, 2018, p. 24).

- Mercados emergentes son principales fuentes de crecimiento (McKinsey\&Company, 2017).

- Foco gubernamental en la modificación de procesos aduaneros, reducción de plazos de liberación de mercancías y control de operaciones de comercio internacional (Ministerio de Economía y Finanzas, 2018, p. 19).

- Dinamismo y crecimiento de la adopción del comercio electrónico.

- Tratado de libre comercio con China y Japón.

- Dinamismo del sector retail e incremento del número de centros comerciales en Lima y provincia (Peñaranda, 2018).

\section{Amenazas}

- Grueso de la población concentrado en los niveles socio económicos a los que no se dirigen principalmente sus marcas (APEIM, 2017).

- Inestabilidad política y evidencia de casos de corrupción en los últimos años.

- Tendencia de compras online enfocada principalmente en productos tecnológicos (Gil, 2018).

- Piratería y contrabando de mercadería textil.

- Consumidor peruano no tiende a realizar sus compras con enfoque en la marca, sólo en el precio (Perú Retail, 2018).

- Informalidad laboral (Redacción Perú21, 2018).

- Presencia de los principales competidores a nivel mundial con más trayectoria en el mercado peruano. 


\section{CAPITULO II: FORMULACIÓN DE LA ESTRATEGIA}

\subsection{Desarrollo y sustentación de la Matriz EFI}

Utilizando la Matriz de Evaluación de Factores Internos, se evaluarán las principales fortalezas y debilidades de Fast Retailing para formular las estrategias acorde a su objetivo de ingreso al mercado peruano en el 2019.

Tabla 2.1

Matriz de Evaluación de Factores Internos

\begin{tabular}{|c|c|c|c|}
\hline & Valor & Clasificación & $\begin{array}{c}\text { Valor } \\
\text { Ponderado }\end{array}$ \\
\hline \multicolumn{4}{|l|}{ Fortalezas } \\
\hline 1. Control total de sus procesos mediante el modelo SPA. & 0.15 & 4 & 0.6 \\
\hline 2. Calidad diferenciada. & 0.18 & 3 & 0.54 \\
\hline 3. Experiencia en el mercado y alto valor de la corporación. & 0.1 & 3 & 0.3 \\
\hline 4. Enfoque en colaboradores y demás socios estratégicos. & 0.12 & 4 & 0.48 \\
\hline 5. Innovación constante en productos y servicio al cliente. & 0.14 & 4 & 0.56 \\
\hline \multicolumn{4}{|l|}{ Debilidades } \\
\hline 1. Misma oferta para todos los mercados. & 0.05 & 2 & 0.1 \\
\hline 2. Alta dependencia económica de una sola marca. & 0.08 & 2 & 0.16 \\
\hline 3. Marcas muy enfocadas en el mercado asiático. & 0.03 & 1 & 0.03 \\
\hline 4. Bajo reconocimiento en mercados donde no participa. & 0.1 & 1 & 0.1 \\
\hline $\begin{array}{l}\text { 5. Obtuvieron presencia en mercados internacionales más } \\
\text { tarde que sus principales competidores. }\end{array}$ & 0.05 & 2 & 0.1 \\
\hline TOTAL & 1 & & 2.97 \\
\hline
\end{tabular}

Fuente: David (2017)

Elaboración propia

Al obtener un resultado de 2.97, por encima del promedio, se podría afirmar que Fast Retailing es una empresa cuya organización interna es sólida, lo que le ha permitido posicionarse en los mercados en los que participa, manejando una organización eficiente y generando un valor de marca, factores que le favorecerían en su tentativa llegada al Perú. 


\subsection{Desarrollo y sustentación de la Matriz EFE}

A continuación se evaluarán los factores identificados en el diagnóstico externo realizado previamente, mediante el modelo de la Matriz de Evaluación de Factores Externos:

Tabla 2.2

Matriz de Evaluación de Factores Externos

\begin{tabular}{|c|c|c|c|}
\hline & Valor & Clasificación & $\begin{array}{c}\text { Valor } \\
\text { Ponderado }\end{array}$ \\
\hline \multicolumn{4}{|l|}{ Oportunidades } \\
\hline 1. Potencial de desarrollo comercial de mercados emergentes. & 0.08 & 3 & 0.24 \\
\hline $\begin{array}{l}\text { 2. Incremento del número de centros comerciales en Lima y } \\
\text { provincia. }\end{array}$ & 0.12 & 3 & 0.36 \\
\hline 3. Tratado de Libre Comercio con Japón. & 0.07 & 4 & 0.28 \\
\hline 4. Incremento en la tendencia del uso del comercio online. & 0.12 & 4 & 0.48 \\
\hline 5. Barreras de ingreso reguladas. & 0.14 & 4 & 0.56 \\
\hline \multicolumn{4}{|l|}{ Amenazas } \\
\hline $\begin{array}{l}\text { 1. Alta rivalidad en el sector y presencia de sus principales } \\
\text { competidores en Perú. }\end{array}$ & 0.15 & 3 & 0.45 \\
\hline 2. Piratería y contrabando. & 0.1 & 1 & 0.1 \\
\hline 3. Alto porcentaje de informalidad laboral. & 0.04 & 1 & 0.04 \\
\hline 4. Inestabilidad política en el gobierno peruano. & 0.08 & 3 & 0.24 \\
\hline $\begin{array}{l}\text { 5. Mayor porcentaje de transacciones online para productos } \\
\text { tecnológicos. }\end{array}$ & 0.1 & 1 & 0.1 \\
\hline TOTAL & 1 & & 2.85 \\
\hline
\end{tabular}

Fuente: David (2017)

Elaboración propia

El resultado final de 2.85 indica que la capacidad de respuesta a los factores del entorno peruano de parte de Fast Retailing, aprovechando las oportunidades y contrarrestando las amenazas, esta por encima del promedio. Este resultado se considera razonable tomando en cuenta la coyuntura del país y el hecho de que sea la primera vez que el grupo inicie un negocio en la región latinoamericana, conociendo un nuevo perfil de consumidor y las normas que rigen las inversiones locales. 


\subsection{Matriz de las Estrategias Genéricas}

Michael Porter propuso en el año 1980 tres estrategias determinadas por la ventaja competitiva de la empresa y su objetivo en el mercado. Fast Retailing obedece principalmente a la estrategia de diferenciación, debido a su especial enfoque en la calidad ofrecida.

Este foco diferenciador que mantiene la empresa como estándar, se centra en 3 pilares. El primero, la calidad del producto, elaborado con materia prima minuciosamente elegida y un proceso de producción muy controlado. En segundo lugar, el servicio al cliente, ya que buscan que la experiencia de este en sus unidades sea gratificante y cómoda. Por ultimo, la relación con la sociedad, siempre buscando velar pos sus beneficios y bienestar (Takeuchi, 2012, p. 11)

La empresa también alcanza costos bajos mediante las economías de escala como consecuencia de la adquisición de materias primas a bajo costo, acompañado por la capacidad de producción en sus fábricas asociadas. Marcas como GU se enfocan en ser líderes en costos, pero por otro lado, marcas como J Brand, Comptoir des Cotonniers y Theory se dirigen a nichos de mercado debido a sus precios elevados y calidad diferenciada de los artículos que ofrecen. En el caso de Uniqlo, el segmento de mercado es más amplio y sin un enfoque tan especializado, debido al precio y estilo casual de sus artículos.

\subsection{Matriz FODA}

En base a la información del análisis interno y externo realizado previamente, se procederá asociar aquellas fortalezas, oportunidades, debilidades y amenazas señaladas con el objetivo de proponer las estrategias que podría implementar Fast Retailing en su llegada al mercado peruano en el año 2019. 
Tabla 2.3

\section{Matriz FODA}

\begin{tabular}{|c|c|c|}
\hline Externo & $\begin{array}{l}\text { FORTALEZAS } \\
\text { 1. Control total de procesos por } \\
\text { el modelo SPA. } \\
\text { 2. Calidad diferenciada. } \\
\text { 3. Experiencia en el mercado. } \\
\text { 4. Alto valor de marca. } \\
\text { 5. Enfoque en socios } \\
\text { estratégicos mediante } \\
\text { condiciones laborales } \\
\text { óptimas, buenas prácticas de } \\
\text { responsabilidad social y } \\
\text { sostenibilidad. } \\
\text { 6. Innovación constante en } \\
\text { productos y servicio al } \\
\text { cliente. } \\
\text { 7. Variedad de marcas dirigidas } \\
\text { a distintos segmentos. }\end{array}$ & \begin{tabular}{ll}
\multicolumn{1}{c}{ DEBILIDADES } \\
1. $\begin{array}{l}\text { Misma oferta para todos } \\
\text { los mercados. }\end{array}$ \\
2. Alta dependencia \\
económica de una sola \\
marca. \\
3. Marcas muy enfocadas en \\
el mercado asiático. \\
4. $\begin{array}{l}\text { Bajo reconocimiento en } \\
\text { mercados donde no } \\
\text { participan. }\end{array}$ \\
5. Llegada tardía y poca \\
presencia en mercados \\
internacionales.
\end{tabular} \\
\hline \begin{tabular}{|l} 
OPORTUNIDADES \\
1. $\begin{array}{l}\text { Potencial de mercados } \\
\text { emergentes. }\end{array}$ \\
2. $\begin{array}{l}\text { Incremento del numero } \\
\text { de Centros }\end{array}$ \\
$\begin{array}{l}\text { Comerciales en Lima y } \\
\text { provincia. } \\
\text { Tratado de Libre }\end{array}$ \\
Comercio con Japón. \\
4. Incremento del uso del \\
comercio electrónico. \\
Barreras de ingreso \\
reguladas.
\end{tabular} & $\begin{array}{l}\text { Estrategias F.O. } \\
\text { F2 - O1: Posicionarse en los } \\
\text { principales Centros Comerciales } \\
\text { diferenciándose por su calidad. } \\
\text { F6 - O4: Mejorar la experiencia } \\
\text { de compra online mediante } \\
\text { soluciones en la elección de } \\
\text { productos y tiempos de entrega. } \\
\text { F7 - O2: Establecer la marca con } \\
\text { la que ingresarán al mercado en } \\
\text { un espacio comercial } \\
\text { correspondiente al segmento } \\
\text { objetivo. } \\
\text { F7 - O4: Oferta de distintas } \\
\text { marcas en el mercado peruano a } \\
\text { través del canal online. }\end{array}$ & $\begin{array}{l}\text { Estrategias D.O. } \\
\text { D4 - O4: Implementar una } \\
\text { estrategia digital previa al } \\
\text { ingreso al mercado para } \\
\text { generar intriga en los } \\
\text { consumidores potenciales y } \\
\text { reforzar el reconocimiento de } \\
\text { la marca en el mercado. } \\
\text { D5 - O3: Importación de } \\
\text { productos al mercado peruano } \\
\text { aprovechando beneficios del } \\
\text { Tratado de Libre Comercio } \\
\text { con Japón. }\end{array}$ \\
\hline 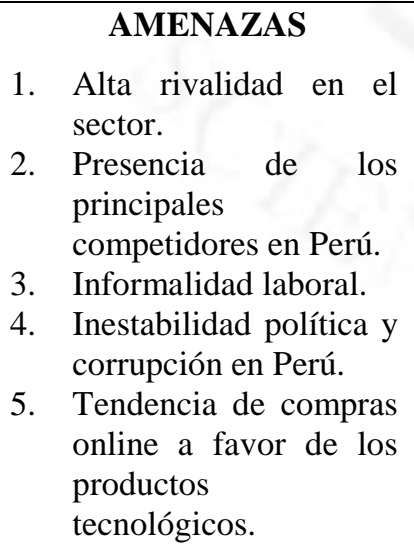 & $\begin{array}{l}\text { Estrategias F.A. } \\
\text { F4 - A1: Ingresar al mercado con } \\
\text { una campaña de marketing que } \\
\text { evidencie el fuerte } \\
\text { posicionamiento de la marca en } \\
\text { otros mercados. } \\
\text { F5 - A3: Aplicar un sistema de } \\
\text { reclutamiento acompañado de un } \\
\text { esquema de beneficios } \\
\text { diferenciado para atraer talento. }\end{array}$ & \begin{tabular}{l}
\multicolumn{3}{c}{ Estrategias D.A. } \\
D1 - A1: Campaña de \\
marketing con beneficios al \\
clientes que refleje la esencia \\
de la marca para atraerlos. \\
D2 - A2: Ingresar al mercado \\
con Uniqlo, su $r$ marca \\
principal, para $r$ ganar \\
participación y asegurar \\
rentabilidad.
\end{tabular} \\
\hline
\end{tabular}

Fuente: Fast Retailing, (2018)

Elaboración propia 


\subsection{Definición y sustentación Visión, Misión y Políticas}

\section{Visión}

La visión que publica actualmente la empresa: "Trabajar siempre por una sociedad mejor y más sostenible.”, se encuentra enfocada en sus buenas prácticas en responsabilidad social y sostenibilidad ambiental. Indican que buscan sacarle el provecho a su operación en la industria para mejorar la calidad de vida de las personas brindándoles prendas con el valor agregado que los caracteriza, evitando dañar el medio ambiente, creando relaciones con todos los grupos de interés, apoyando a las sociedades impactadas mediante el empleo, respetando sus derechos, y brindando condiciones laborales óptimas bajo lineamientos de seguridad y salud (Fast Retailing, 2018).

\section{Misión}

La misión que publica el grupo está claramente enfocada hoy en día en dos pilares: el producto y el desarrollo de sus socios estratégicos. Indican que buscan crear prendas de vestir que le causen satisfacción al usuario por el valor único que ofrecen y crecer como empresa en línea con la sociedad y el bienestar de las personas (Fast Retailing, 2018).

\section{Políticas}

Las políticas por las que se rige Fast Retailing en la actualidad se encuentran reflejadas en el Código de Conducta que publican, el cual aplica para todos los colaboradores, directores, productores y subsidiarias. Se maneja bajo los principios de satisfacción del cliente, políticas en contra de la discriminación o acoso, respeto a las leyes de cada mercado, relaciones óptimas con socios estratégicos, manejo apropiado de información y divulgación de esta en caso sea necesario, foco en las condiciones laborales, protección de los recursos y del medio ambiente, contribución a la sociedad, y distinción de la vida privada con la laboral. (Fast Retailing, 2018).

\subsection{Definición de los Objetivos Estratégicos de la Empresa}

- Ingresar a la región latinoamericana año 2019, mediante la apertura de una tienda ancla en Lima para iniciar su posicionamiento en la región. 
- Vender 60 mil millones de dólares para el año 2020 (Takeuchi, 2012, p. 1)

- Lograr 253.000 millones de dólares de facturación para el año 2030 (Perú Retail, 2015)

- Crecer anualmente en un $20 \%$ y obtener un $20 \%$ de beneficio en la operación (Takeuchi, 2012, p. 1).

- Contar con un 30\% de cargos gerenciales de la organización ocupados por mujeres para el 2020 (Fast Retailing, 2018).

- Reducir la huella ecológica del impacto de su operación, reduciendo el consumo de agua en un $15 \%$ y de energía en un $10 \%$ en sus fábricas para el 2020, en comparación al 2016 (Fast Retailing, 2018, p. 28).

Eliminar totalmente las emisiones de sustancias químicas peligrosas para Enero del 2020 (Fast Retailing, 2018, p. 37).

- Lograr un crecimiento anual del 30\% hasta el año 2022 en el negocio de Uniqlo Sudeste Asiático y Oceanía (Fast Retailing, 2018).

- Contar con una red de más de 1000 tiendas en el negocio de Uniqlo China para el año 2021 (Fast Retailing, 2018).

\subsection{Redefinición o creación de nuevas UEN}

En la actualidad, Fast Retailing cuenta con unidades estratégicas en el negocio divididas en: Uniqlo (Internacional y Japón), GU, y Marcas Globales. Por otro lado, cuentan con dos operaciones no relacionadas llamadas Wearex y On Hand (Fast Retailing, 2018).

Como propuesta para la redefinición, Fast Retailing podría optar por organizar sus marcas globales en unidades estratégicas de negocio según público objetivo de manera que se agrupen aquellas que se dirijan a un mercado mas homogéneo, lo cual facilitaría la toma de decisiones a nivel macro y no sólo por marca. En ese contexto, se consideraría aún a Uniqlo como una unidad separada debido a la dependencia que tiene el grupo de esta marca. La composición sería: "División Uniqlo" (Uniqlo Internacional y Uniqlo Japón), "División Premium” (J Brand, Theory, Helmut Lang y Comptoir des Cotonniers), "División Estándar" (Pricesse Tam Tam y PLST), "División Precios Bajos” (GU) y “División de No Relacionados” (Wearex y On Hand). 


\subsection{Propuesta y sustentación de Estrategias}

\section{Ambiente Global}

Existen cuatro estrategias básicas que se rigen en relación a la presión para bajar costos y la capacidad de responder al mercado local, las cuales son: estandarización global, internacional, transnacional y de adaptación local (Hills et alt., 2015, p. 262).

Actualmente la operación de Fast Retailing obedece a una estrategia de estandarización global para marcas como Uniqlo, ya que no adaptan los productos al mercado al que se dirigen y se rigen bajo una misma oferta a nivel mundial. La presión para bajar sus costos también se considera alta, tomando en cuenta la presencia de sus principales competidores en los mercados a los que se dirige. A pesar de ello, se considera que la empresa debería mantener esta estrategia ya que, en gran parte, le ha permitido mantener sus estándares de calidad a nivel global y posicionarse en los consumidores por su esencia de marca.

\section{Corporativas}

A lo largo de los años, ha presentado diversas estrategias corporativas que le han permitido ampliar su oferta en el mercado y reforzar el nombre de la marca. Desarrollaron la estrategia de diversificación relacionada con la creación de G.U. Co. en el 2006, para desarrollar la marca GU. Por otro lado, se han integrado horizontalmente con empresas del sector retail de moda como lo hicieron con Theory en el 2004 y Comptoir des Cotonniers en el 2005. En el 2006 adquirió a la marca Princesse Tam.Tam y en el 2012 el control mayoritario de J Brand Holdings.

También se han diversificado de manera no relacionada, adquiriendo en el 2002 la empresa de alimentos frescos SKIP, la cual mantuvieron por dos años. Actualmente cuentan con Wearex, una compañía de soluciones digitales, y On Hand, del negocio de los almacenes (Fast Retailing, 2018). Además, la empresa cuenta con alianzas estratégicas con sus socios de fabricación y Joint Ventures, por ejemplo, con la compañía operadora de retail Wing Tai Retail de Singapur con el objetivo de expandir su operación en el país (Fast Retailing, 2018). 


\section{De Negocios}

La inversión a nivel de negocios de Fast Retailing se sustenta en base a una posición competitiva fuerte, debido a que cuenta con marcas que compiten directamente con las lideres en su sector, y una demanda en crecimiento para los distintos segmentos de mercado a los que se dirigen.

La empresa podría aprovechar estos dos factores para aplicar una estrategia de crecimiento, la cual según la matriz presentada por Igor Ansoff en 1957, obedecería a una estrategia de desarrollo de mercado, introduciendo sus productos ya existentes a mercados nuevos, especialmente en regiones en las que no opera actualmente.

\section{Funcionales}

La compañía cuenta con diversas estrategias relacionadas a sus actividades primarias y de apoyo. Por ejemplo, en el área de Marketing, como medio de publicidad realizan auspicios a deportistas reconocidos, como en el caso de Roger Federer. Además de eso, cuenta con convenios con marcas como Disney, que le permiten lanzar al mercado líneas como "Magic For All” de Uniqlo con diseños elaborados por Andy Warhol.

En cuanto al a las estrategias de gestión de personas, la compañía cuenta con canales de comunicación abiertos a disposición del colaborador así como con sistemas de reclutamiento interno para recolocaciones. Además, en Octubre del 2017 adaptaron un nuevo método de evaluación de desempeño junto con un sistema de calificación global para que las evaluaciones y remuneraciones puedan ser más justas y transparentes. Por otro lado, el FRMIC (Fast Retailing Management and Innovation Center) fundado en el 2009 con el propósito de formar líderes para la compañía, cuenta en la actualidad con un programa de entrenamiento de 10 años para sus colaboradores en el cual se desarrollan temas relacionados a los valores y filosofía de la compañía, resolución de problemas, estrategia de ventas, entre otros. Además cuentan con el "Future Global Leaders Program" dirigido para colaboradores con puestos gerenciales alrededor del mundo, y el proyecto "Mirai" el cual busca despertar en los colaboradores la capacidad de generar nuevas ideas de negocio (Fast Retailing, 2018). 


\section{CAPÍTULO III: IMPLEMENTACIÓN ESTRATÉGICA}

\subsection{Evaluación del rediseño de la estructura organizacional de la empresa}

Tadashi Yanai se rige mediante la filosofía de "Zen - in Keiei”, por lo que se entiende que todas las marcas que maneja Fast Retailing funcionan con la misma estructura y estándar. A lo largo de los años han demostrado que un foco de la corporación es el empoderamiento de sus colaboradores, retando a que independientemente del puesto que tenga uno, se enfrente a situaciones en las que tenga que tomar decisiones diarias bajo un criterio de nivel directivo (Takeuchi, 2012, pp. 15 - 16).

Figura 3.1

Estructura Organizacional Propuesta

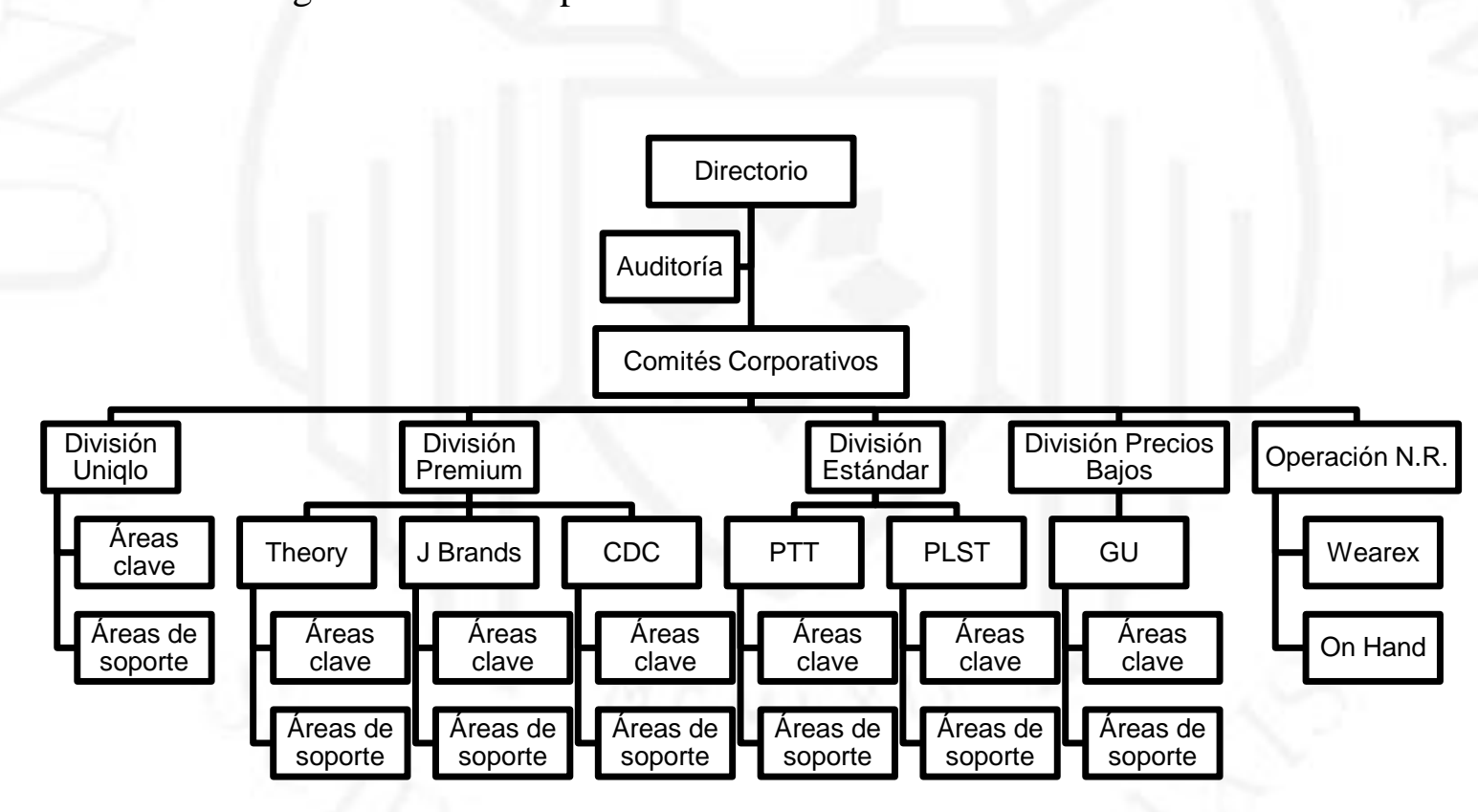

Elaboración propia

Es de conocimiento público que la corporación trabaja bajo los lineamientos de comités de recursos humanos, sostenibilidad, ética, código de conducta, derechos humanos e inversión en tecnologías de información, los cuales trabajan directamente con cada marca y oficinas de distintos países (Fast Retailing, 2018). Tomando en 
consideración el hecho de que se rigen bajo un gobierno corporativo que decanta información a cada una de las empresas, se propone para la el rediseño de UEN propuesto, la definición de un organigrama por unidad estratégica de negocios respetando el soporte de dichos comités para todas las marcas, lo cual se replicaría en todos los territorios en los que cuenten con oficinas corporativas con el objetivo de optimizar la productividad. Cada una de las empresas se encontraría conformada por sus áreas clave (operaciones, logística, comercial, marketing) y de apoyo (recursos humanos, contabilidad y finanzas, responsabilidad social).

\subsection{Propuesta de cambios}

Como propuesta de cambios para la operación en el mercado peruano en el año 2019, además del rediseño de las unidades estratégicas de negocio, la empresa podría optar por enfocar su operación en dos temas específicos, desarrollando una área independiente para el canal de ventas por Internet y enfocándose localmente en cuanto a Responsabilidad Social Empresarial.

En cuanto al canal de ventas por Internet, considerando la situación actual de desarrollo del comercio electrónico, sería conveniente que refuercen este medio de comunicación y venta directa para poder llegar no sólo al consumidor de Lima, sino también a diversos sectores del país y Sudamérica. Se debe trabajar de la mano con equipos comerciales, de operaciones y de logística para hacer de este un canal eficiente y fácil de usar para el cliente, que asegure la disponibilidad de los productos que ofrece, contando con líneas exclusivas para este canal y estableciendo plazos de entrega y costos razonables, de manera que se perciba el servicio de calidad que los caracteriza.

Además, el área de Marketing podría enfocarse en la Responsabilidad Social Empresarial como medio para poder hacer el contacto directo con las comunidades y apoyar en lo necesario. Se deben desarrollar estrategias estacionales de ayuda social para poder apoyar a las zonas más necesitadas del país, y también con foco en el cuidado del medio ambiente. El hecho de que esté relacionada al área de Marketing le permitirá a la marca reforzar su posicionamiento, generar conciencia, y establecer actividades de ayuda que convoquen a un buen número de clientes o clientes potenciales a la marca. 


\section{CAPÍTULO IV: CONTROL ESTRATÉGICO}

\subsection{Diseño de un Mapa Estratégico de Control}

En el año 1992, Robert S. Kaplan y David P. Norton publicaron el concepto del "Balance Score Card", una herramienta de evaluación del desempeño de la compañía desde cuatro perspectivas organizacionales (Kaplan y Norton, 2007). A continuación se presentará el mapa estratégico de control de elaboración propia para la empresa Fast Retailing.

Figura 4.1

Mapa Estratégico de Control

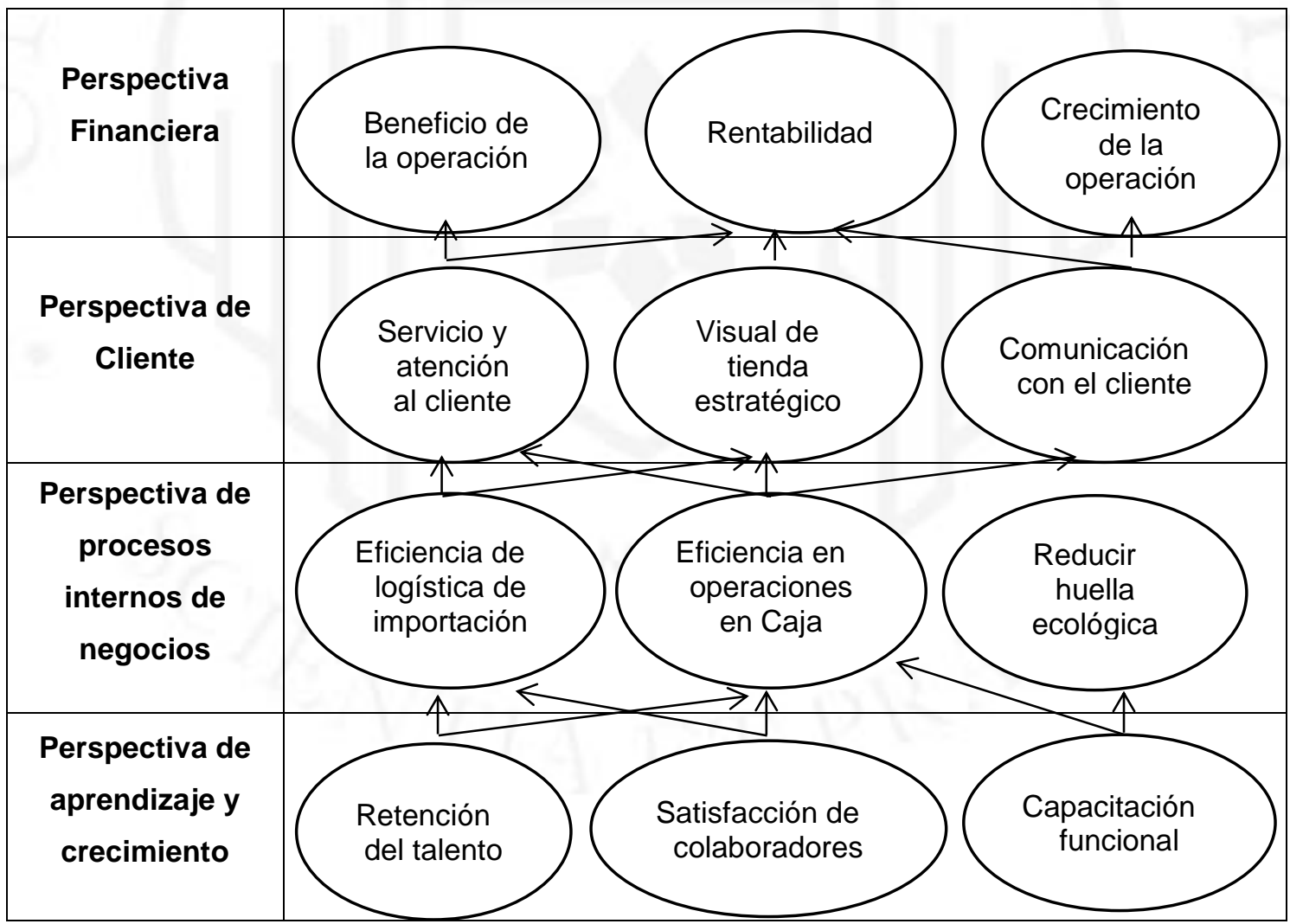

Fuente: Kaplan y Norton (1996)

Elaboración propia 


\subsection{Desarrollo de un Cuadro de Mando Integral}

A continuación, en base al Mapa Estratégico de Control propuesto, se señalarán aquellos indicadores de gestión que permitirían medir las acciones necesarias para cumplir con los objetivos propuestos para cada perspectiva.

Tabla 4.1

Cuadro de Mando Integral

\begin{tabular}{|c|c|c|c|}
\hline Perspectiva & Objetivo & Indicador & Peso \\
\hline \multirow{5}{*}{ Financiera } & Rentabilidad & Margen neto & $100 \%$ \\
\hline & Venta & $\begin{array}{c}\text { Venta } \\
\text { Rotación de inventarios } \\
\text { Ticket promedio de compra }\end{array}$ & $\begin{array}{l}50 \% \\
25 \% \\
25 \%\end{array}$ \\
\hline & Beneficio de la operación & Utilidad & $100 \%$ \\
\hline & $\begin{array}{l}\text { Retorno del capital } \\
\text { invertido }\end{array}$ & ROI (Retorno a la Inversión) & $100 \%$ \\
\hline & $\begin{array}{l}\text { Crecimiento de la } \\
\text { operación }\end{array}$ & Crecimiento en venta & $100 \%$ \\
\hline \multirow{3}{*}{ De cliente } & $\begin{array}{l}\text { Servicio y atención al } \\
\text { cliente }\end{array}$ & $\begin{array}{c}\text { Encuesta de satisfacción } \\
\text { Número de reclamos por mes }\end{array}$ & $\begin{array}{l}70 \% \\
30 \%\end{array}$ \\
\hline & $\begin{array}{l}\text { Visual de tienda } \\
\text { estratégico }\end{array}$ & Rotación de productos en vitrina & $100 \%$ \\
\hline & $\begin{array}{c}\text { Comunicación con el } \\
\text { cliente }\end{array}$ & $\begin{array}{l}\text { Mails de clientes registrados } \\
\text { Tasa de conversión en mailing }\end{array}$ & $\begin{array}{l}25 \% \\
75 \%\end{array}$ \\
\hline \multirow{3}{*}{$\begin{array}{l}\text { De procesos } \\
\text { internos }\end{array}$} & $\begin{array}{c}\text { Eficiencia en logística de } \\
\text { importación }\end{array}$ & $\begin{array}{l}\text { Tiempo de recepción de lotes } \\
\text { Costo de importación de lotes }\end{array}$ & $\begin{array}{l}50 \% \\
50 \%\end{array}$ \\
\hline & $\begin{array}{l}\text { Eficiencia en operaciones } \\
\text { en caja }\end{array}$ & $\begin{array}{l}\text { Timbrado de productos por hora } \\
\text { Clientes atendidos por hora }\end{array}$ & $\begin{array}{l}60 \% \\
40 \% \\
\end{array}$ \\
\hline & $\begin{array}{l}\text { Reducción de la huella } \\
\text { ecológica }\end{array}$ & $\begin{array}{l}\text { Utilización de recursos: agua } \\
\text { Utilización de recursos: energía }\end{array}$ & $\begin{array}{l}50 \% \\
50 \%\end{array}$ \\
\hline \multirow{3}{*}{$\begin{array}{l}\text { De } \\
\text { aprendizaje y } \\
\text { crecimiento }\end{array}$} & Retención del talento & $\begin{array}{l}\text { Rotación de personal según } \\
\text { calificación de evaluación }\end{array}$ & $100 \%$ \\
\hline & $\begin{array}{l}\text { Satisfacción de } \\
\text { colaboradores }\end{array}$ & Encuesta de clima laboral & $100 \%$ \\
\hline & Capacitación funcional & $\begin{array}{l}\text { Incremento en la productividad } \\
\text { Satisfacción de la capacitación }\end{array}$ & $\begin{array}{l}30 \% \\
70 \%\end{array}$ \\
\hline
\end{tabular}

Fuente: Kaplan y Norton (1996)

Elaboración propia

Como se mencionó anteriormente, Fast Retailing busca llegar a una meta de ventas determinada para el año 2020, así como también contar con un porcentaje de beneficio de su operación de $20 \%$ y un crecimiento anual del 20\%. En línea con esto, en cuanto a la perspectiva financiera de esta nueva operación, se tendrá como objetivo lograr la rentabilidad cumpliendo con los objetivos de venta y de retorno de la 
inversión. La rotación de inventarios y el ticket promedio de compra permitirán tener información de primera mano sobre el control del abastecimiento en la tienda y la liberación de mercadería relacionada a las ventas. Se podrá determinar el beneficio que trae esta nueva operación utilizando como indicador la utilidad y de esta manera conocer un detalle de la ganancia o pérdida de la misma.

Para los clientes, aplicar una encuesta de satisfacción y medir la cantidad de reclamos al mes ayudará a conocer la percepción de servicio y el nivel de respuesta de los colaboradores a sus necesidades. El visual de la tienda es un factor en el que tendrán que enfocarse y se podrá medir su eficiencia mediante el control de la rotación de los productos en las principales ubicaciones del layout de la tienda. La comunicación con los clientes a través del correo se podrá medir mediante la cantidad de clientes registrado en la base de datos, y la tasa de conversión de compras por mail mediante códigos de descuento o registro en la plataforma online.

Dos procesos internos clave serian los logísticos y la operación en tienda. La logística de importación podría medirse con el tiempo que demora la recepción de lotes de colecciones y el costo del mismo. Por otro lado, la operación en cajas podría medirse con el control de la rapidez de los productos timbrados y la cantidad de clientes atendidos por hora. Además, alineados a los objetivos organizacionales de Fast Retailing, se medirá el impacto de la huella ecológica de la operación mediante el control de la utilización de recursos como agua y energía.

En la perspectiva de aprendizaje tenemos tres objetivos centrados en el personal. La retención del talento se mediría en base a los resultados de la evaluación de desempeño y el control de la rotación de los colaboradores con mejor calificación en este proceso de evaluación. Mediante la encuesta de clima laboral se podrá obtener una idea aterrizada del nivel de satisfacción de los colaboradores en la empresa en temas de beneficios, cultura, equidad, condiciones laborales, entre otros. Por último, la efectividad de las capacitaciones por función podrá medirse mediante una encuesta de satisfacción al colaborador, y la opinión del jefe directo en base a la mejora del rendimiento o productividad del colaborador en los temas tratados en el entrenamiento. 


\section{CONCLUSIONES}

Luego de llevar a cabo el análisis estratégico presentado previamente, se puede concluir que Fast Retailing es una organización sólida, cuya extensa trayectoria e implementación de distintas estrategias de negocio, le han permitido alcanzar resultados beneficiosos en los mercados en los que opera.

Su minucioso enfoque en los estándares de calidad de sus productos y la segmentación de sus marcas con enfoque a distintos públicos, han impactado en la consolidación de las mismas, compitiendo con marcas líderes en el mercado y fidelizando a sus clientes a través de una oferta de productos innovadora y confiable. Por otro lado, la empresa ha logrado ser líder en costos en marcas no especializadas a través de la producción a escala y utilización de materias primas de bajo costo, impactando en la rentabilidad de las mismas.

Adicional a ello, el grupo presta especial importancia al desarrollo de una cultura organizacional solida en beneficio de sus colaboradores. La implementación de diversos programas relacionados a la gestión de su capital humano en relación a su retención, remuneraciones, formación para todos los niveles de la organización y desarrollo del talento impactan en el desempeño del personal de Fast Retailing, contando con personas que estén a gusto con su trabajo, capacitadas y que perciban la oportunidad de crecimiento dentro de la empresa.

El desarrollo de distintas estrategias corporativas de diversificación, integración, fusiones y adquisiciones, han permitido que el grupo pueda tener presencia en nuevos mercados e industrias, creciendo exponencialmente a lo largo de los años y ampliando su operación en el sector de retail. Fast Retailing evidencia su intención de expandir sus marcas, y el tentativo ingreso al mercado peruano en el año 2019 podría concretarse con éxito considerando algunas recomendaciones que se mencionarán a continuación. 


\section{RECOMENDACIONES}

La opción más recomendable para Fast Retailing es la de ingresar al mercado peruano en el 2019 únicamente con su marca Uniqlo. Esto, debido a que es la marca con la que tienen más experiencia en mercados extranjeros, mayor trayectoria, y mayor posicionamiento a nivel global. Dependiendo de los resultados de esta operación podrán evaluar la opción de ingresar con otras marcas a largo plazo, al estar más familiarizados con el mercado de la región latinoamericana.

Considerando el ingreso de Fast Retailing al mercado peruano en el 2019, la empresa deberá adoptar estrategias que le permitan adaptarse al entorno y desarrollar la marca de manera exitosa en este mercado nuevo para ellos. El ingreso al país sería mediante una subsidiaria de propiedad total, de manera que puedan mantener los lineamientos corporativos al concretar la instalación completa de su sucursal en Perú a través de una tienda ancla en Lima, considerando que el Perú es un país centralizado donde el grueso del público de los niveles socioeconómicos al que se dirigiría se encuentra concentrado en la capital.

Fast Retailing tendrá que estudiar minuciosamente el perfil del consumidor peruano y latino, considerando que no tienen experiencia en esta región, tomando en cuenta sus tendencias de compra, prioridades y preferencias. Por otro lado, respetando los lineamientos corporativos, un foco muy importante será el impacto en la responsabilidad social, ejecutando programas de ayuda social a las comunidades y empleando en un porcentaje mayoritario a peruanos. Estas actividades deberán adaptarse a la realidad peruana, realizando programas de apoyo social en zonas vulnerables, apoyando con campañas de abrigo para las regiones más frías del país, e instaurando programas de cuidado al medio ambiente dirigidas al control de los desperdicios.

Para lograr posicionamiento en el sector fast fashion de Perú, la marca deberá reforzar sus campañas de marketing enfocadas en el cliente peruano, mediante publicidad en los medios masivos más populares o patrocinio a personajes icónicos del deporte o de la moda, como hacen a nivel mundial. El visual de la tienda tiene que ser 
considerado como un foco estratégico de manera que sea atractivo para el nuevo consumidor y logre generar ventas. En cuanto a la logística, el tiempo de aprovisionamiento de lotes deberá ser rápido para no dejar demanda desatendida, y lo ideal sería que el servicio de ventas online se active a nivel de Latinoamérica considerando que este seria el punto de partida para su operación en la región.

Por último, para captar al mejor talento se trabajará con foco en la selección del personal, aprendizaje y desarrollo. Mediante programas de atracción del personal potentes, beneficios corporativos, capacitaciones continuas en habilidades blandas y técnicas, programas de reconocimiento por objetivos, desarrollo de planes de carrera para puestos selectos de la organización, enfoque en el clima y cultura organizacional, una evaluación de desempeño efectiva y el refuerzo del feedback continuo, la empresa podrá fidelizar a sus colaboradores con el objetivo de evitar una alta rotación del personal que afecte en gran medida su operación y la productividad de esta, logrando de esta manera el refuerzo de la solidez de su estructura organizativa en cada territorio en el que opera.

Se considera que esta operación podría ser exitosa en la medida que la empresa tome en consideración todos los factores que influencian a este nuevo mercado, para poder aprovechar influencias de ellos mediante la aplicación de estrategias enfocadas en cada una de sus necesidades. 


\section{REFERENCIAS BIBLIOGRÁFICAS}

Andina Agencia Peruana de Noticias. (03 de Octubre de 2018). Perú sin reformas política y judicial no será más atractivo para inversiones. Recuperado de andina.pe/agencia/noticia-peru-sin-reformas-politica-y-judicial-no-sera-masatractivo-para-inversiones-727320.aspx

APEIM (Agosto de 2017). Niveles Socioeconómicos 2017. Recuperado de http://www.apeim.com.pe/wp-content/themes/apeim/docs/nse/APEIM-NSE2017.pdf

Business Insider. (03 de Agosto de 2017). Uniqlo will sell clothes out of vending machines in airports across the US. Recuperado de www.businessinsider.com/uniqlo-adds-vending-machines-airports-malls-2017-8

Bloomberg. (17 de Octubre de 2018). Bloomberg Billionaires Index. Recuperado de www.bloomberg.com/billionaires/profiles/tadashi-yanai/

Comptoir des Cotonniers. (s.f.). About us Comptoir des Cotonniers. Recuperado de www.comptoirdescotonniers.eu/la-marque-c84

David, Fred R. (2017). Conceptos de Administración Estratégica. Ciudad de México, México: Pearson Education.

Diario Gestión. (31 de Mayo de 2018). Gamarra prevé facturar más de s/2000 millones en prendas mundialistas. Recuperado de gestion.pe/economia/gamarra-prevefacturar-s-2-000-millones-prendas-mundialistas-234881

Diario Gestión. (28 de Abril de 2018). ¿Cómo afecta la pirateria al Perú?. Recuperado de gestion.pe/economia/afecta-pirateria-peru-232501

Diario Perú21. (20 de Julio de 2018). Informalidad laboral se redujo de 57.8\% a 46.5\% en los últimos 12 años. Recuperado de peru21.pe/economia/informalidadlaboral-redujo-57-8-46-5-ultimos-12-anos

Fast Retailing. (10 de Septiembre de 2018). About Fast Retailing. Recuperado de www.fastretailing.com/eng/about/ 
Fast Retailing. (15 de Octubre de 2018). Group Companies Fast Retailing. Recuperado de https://www.fastretailing.com/eng/group/

Fast Retailing. (18 de Octubre de 2018). Investor Relations Fast Retailing. Recuperado de www.fastretailing.com/eng/ir/

Fast Retailing. (07 de Septiembre de 2018). Sustainability Fast Retailing. Recuperado de www.fastretailing.com/eng/sustainability/

Fast Retailing. (Febrero de 2018). Sustainability Report 2018 Fast Retailing. recuperado de https://www.fastretailing.com/eng/sustainability/report/new.html

Forbes. (23 de Mayo de 2018). The World's Most Valuable Brands. Recuperado de www.forbes.com/powerful-brands/list/3/\#tab:rank

GU. (s.f.). $G U$. Recuperado de www.gu-japan.com/jp/pc/

Gil, F. (18 de Septiembre de 2018). Más de 5 millones de peruanos compran por internet, según OLX Perú. Diario Gestión. Recuperado de gestion.pe/tecnologia/5-millones-peruanos-compran-internet-olx-peru-244613

Kaplan, R. y Norton D. (Julio de 2007). Usar el Balanced Scorecard como un sistema de gestión estratégica. Harvard Business Review, p 2.

Kaplan, R. y Norton D. (1996). The Balanced Scorecard: Translating Strategy into Action. Estados Unidos: Havard Business Review.

Heritage. (2018). 2018 Index of Economic Freedom. Recuperado de www.heritage.org/index/country/peru

Hills, C., Jones, G., y Schilling, M. (2015). Administracion Estrategica: teoria y casos. Un enfoque integral (11va edicion ed.). Mexico D.F., Mexico: CENGAGE Learning.

J Brand. (s.f.). Our Story J Brand. Recuperado de www.jbrandjeans.com/company-bio

McKinsey\&Company. (Mayo de 2018). Faster fashion: How to shorten the apparel calendar. Recuperado de www.mckinsey.com/industries/retail/ourinsights/faster-fashion-how-to-shorten-the-apparel-calendar

McKinsey\&Company. (Noviembre de 2017). The State of Fashion 2018: Renewed optimism for the fashion industry. Recuperado de 
www.mckinsey.com/industries/retail/our-insights/renewed-optimism-for-thefashion-industry

Ministerio de Comercio Exterior y Turismo. (s.f.). Acuerdos Comerciales. Recuperado de http://www.acuerdoscomerciales.gob.pe/

Ministerio de Economía y Finanzas. (27 de Abril de 2018). Informe de actualizacion de proyecciones Macroeconómicas. 2018-2021 p.21.

Osterwalder, A. y Pigneur, Y. (2010). Business Model Generation. Nueva Jersey, Estados Unidos: Wiley.

Peñaranda, C. (27 de Agosto de 2018). Sector comercio sigue en constante expansión. Camara de Comercio de Lima. Recuperado de www.camaralima.org.pe/repositorioaps/0/0/par/r842_1/informe\%20economico

Perú Retail. (18 de Marzo de 2015). Fast Retailing fija nueva meta de ventas hasta 2030. Recuperado de www.peru-retail.com/fast-retailing-fija-una-nueva-metade-ventas-hasta-2030/

Perú Retail. (28 de Junio de 2018). ¿Cuál es el perfil del consumidor peruano?. Recuperado de www.peru-retail.com/perfil-consumidor-peruano

Perú Retail. (23 de Agosto de 2018). Escenario del comercio electronico en el mercado peruano. Recuperado de www.peru-retail.com/escenario-comercio-electronicomercado-peruano/

Perú Retail. (21 de Septiembre de 2018). Perú: Ventas en centros comerciales crecerian $7.3 \%$ a fines del 2018. Recuperado de www.peru-retail.com/peruventas-centros-comerciales-2018/

Princesse Tam Tam. (s.f.). Brand Princesse Tam Tam. Recuperado de www.princessetamtam.com/en/the-brand-p23

Sherman, L. (18 de Julio de 2017). Theory 2.0, Andrew Rosen's Millenial Experiment. Business of Fashion. Recuperado de www.businessoffashion.com/articles/bofexclusive/theory-2-0-andrew-rosen-millennial-strategy

Takeuchi, H. (2012). Grupo Fast Retailing (caso 713-S21). Recupeado del sitio de internet de Universidad Harvard, Escuela de Negocios: https://www.harvard.edu/ 
Theory. (s.f.). About Us. Recuperado de www.theory.com/about-us

Uniqlo. (s.f.). Who we are. Recuperado de www.uniqlo.com/us/en/company/who-weare 
ANEXOS 


\title{
Anexo 1: The duration of an end to end fashion cycle widely varies by company
}

\author{
The duration of an end-to-end fashion cycle widely varies by company. \\ Fashion cycle duration, weeks \\ Planning, design, and product development $\quad$ Sell-in $\square$ Production and delivery \\ Global hybrid fashion company \\ Global denim company

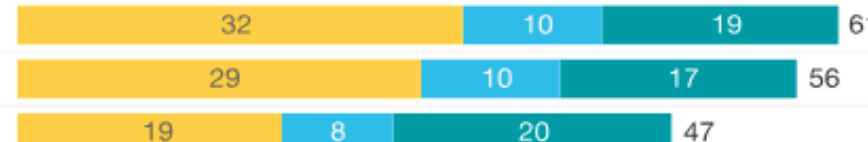 \\ Global premium apparel brand \\ European hybrid brand \\ 22

2 \\ 20

\begin{tabular}{|c|c|c|}
\hline 12 & 6 & 18 \\
\hline
\end{tabular} \\ Global premium lifestyle brand \\ US lifestyle brand

\begin{tabular}{l|l|l|l}
15 & 2 & 17 & 34
\end{tabular} \\ Global vertical fast-fashion brand 112 \\ Approximate. \\ McKinsey\&Company
}

Fuente: McKinsey\&Company (2018) 